\title{
Report of surgical correction of a cervicovaginal agenesis case: cervicovaginal reconstruction with pudendal thigh flaps
}

Remzi Abali', Samet Vasfi Kuvat ${ }^{2}$, Serpil Bozkurt ${ }^{3}$, Arda Kayhann ${ }^{4}$, Mehmet Aytac Yuksel', Hatice Caliskan ${ }^{1}$

'Department of Gynecology and Obstetrics, Faculty of Medicine, Namik Kemal University, Turkey

2Department of Plastic, Reconstructive and Aesthetic Surgery, Faculty of Medicine, Istanbul University, Turkey

${ }^{3}$ Department of Gynecology and Obstetrics, Faculty of Medicine, Maltepe University, Turkey

"Department of Radiology, Faculty of Medicine, Namik Kemal University, Turkey sDepartment of Gynecology and Obstetrics, Cerrahpasa Medical Faculty, Istanbul University, Turkey

Submitted: 28 October 2010

Accepted: 9 April 2011

Arch Med Sci 2013; 9, 1: 184-187

DOI: 10.5114/aoms.2013.33071

Copyright (๑) 2013 Termedia \& Banach

Congenital agenesis of the uterine cervix and vagina in the presence of a functional endometrium is an extremely rare mullerian anomaly [1]. Congenital vaginal agenesis occurs with a prevalence of 1/4000-1/5000 live-born females, while the accurate incidence of cervicovaginal agenesis is controversial [1-3]. Cervicovaginal agenesis is usually not diagnosed until menarche. It is manifested by the collection of menstrual blood in the functional endometrium, Fallopian tubes and peritoneal cavity, leading to primary amenorrhea and cyclic abdominal pain [1, 4].

The primary goal of cervicovaginal reconstruction in cervicovaginal agenesis cases is to preserve reproductive performance [5-8]. In routine clinical practice, hysterectomy was advised in cases with complete cervical aplasia, to control pain and dysmenorrhea and also prevent complications such as peritonitis $[4,9,10]$. But recent studies are more encouraging [3]. However, as different techniques were performed for each individual type of cervical agenesis case, there is great controversy as to the best technique because each has associated advantages and disadvantages.

In this case report, a functional reconstruction with pudendal thigh flaps complicated with endometrioma and hematosalpinx in a cervicovaginal agenesis case will be discussed in the light of the literature.

An 18-year-old virgin woman with a history of primary amenorrhea and cyclic abdominal pain was referred to our gynecology clinic with normal secondary sex characteristics. Adrenarche and thelarche had occurred by age 13 years. Physical examination revealed no abnormalities. The vagina ended with a $1 \mathrm{~cm}$ blind pouch. A pelvic sonographic examination showed an abnormally enlarged uterus due to hematometra and also a left ovarian endometrioma. No cervical tissue was observed in inspection or sonographic imaging, indicating complete cervical agenesis. The intravenous pyelogram showed a normal urinary tract system. Magnetic resonance imaging (MRI) revealed an arcuate uterus and a normal endometrial cavity with complete cervical agenesis (Figure 1). The laboratory work-up showed normal serum levels of follicle-stimulating hormone, thyroid-stimu-
Corresponding author: Remzi Abali MD Department of Gynecology and Obstetrics Faculty of Medicine Namik Kemal University 100. yil Mah. Barbaros Cad No: 132, Tekirdag, Turkey Phone: +90 282 2620130, +90 5327315360 Fax: +90 2822626810 E-mail: remziabali@yahoo.com 
lating hormone, and prolactin. The karyotype was $46, X X$. The patient was informed about the procedure and informed consent was obtained.

Bilateral posterior neurovascular pudendal thigh flaps were planned. The course of the superficial perineal artery and the flap dimensions (approximately $11 \mathrm{~cm} \times 3.5 \mathrm{~cm}$ ) were marked.

The procedure was performed with a semilithotomy position allowing both abdominal and perineal approaches. A medial vertical incision parallel to the groin crease was made. A lateral vertical incision was placed, depending on the necessary size of the flap ( $8 \mathrm{~cm}$ width in our case). During dissection, the deep fascia of the thigh and epimysium of the muscles were included with the flaps (Figure 2). An incision of $1.5 \mathrm{~cm}$ diameter was made on the uterine fundus with a $10-\mathrm{mm}$ dilator via the abdominal approach (Figure 3). This maneuver helped to identify the upper limit of the atretic tissue of the cervix. The atretic cervical tissue was resected and a blunt dissection was performed between the bladder and the rectum to form a normal vaginal pouch. After the primary coverage of the donor sites, the flaps were then delivered medially through a channel between the pivot point (posterior of the flaps) and the neovaginal area.

The flaps were conjoined with polyglycolic acid sutures at anterior and posterior zones of the neovagina. The apexes of the combined flaps were sutured to the uterus with stitches of 2-0 polyglactin. The left ovarian endometrioma was excised. The bilateral closed fimbrial ends were also opened by fimbrioplasty. A $16 \mathrm{CH}$ Foley catheter was inserted into the uterine cavity for 20 days. The cavity was irrigated with saline and $10 \%$ povidone-iodine during this period.

Antibiotic prophylaxis (ampicillin) was maintained for 14 days. Low-molecular-weight heparin prophylaxis was administered for 7 days. No mold was required. There were no complications in the early postoperative period. The patient was discharged on the $20^{\text {th }}$ day with no complications. The patient was assessed postoperatively at 1, 3, 6 and 12 months.

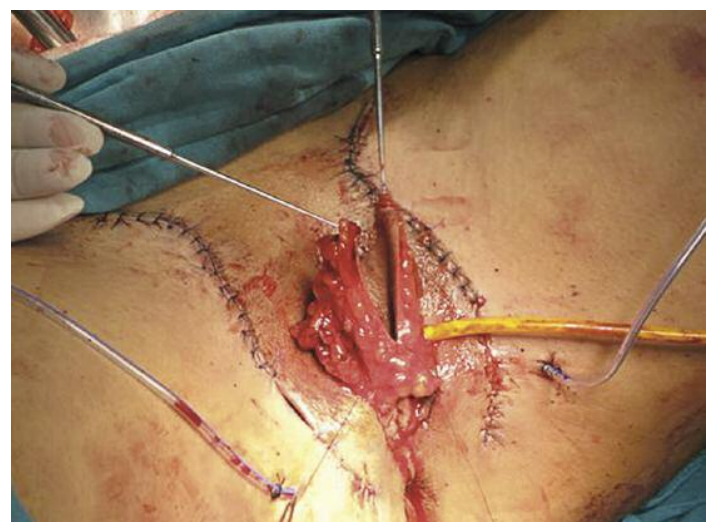

Figure 2. Creation of utero-vaginal anastomosis via $10 \mathrm{~mm}$ dilator

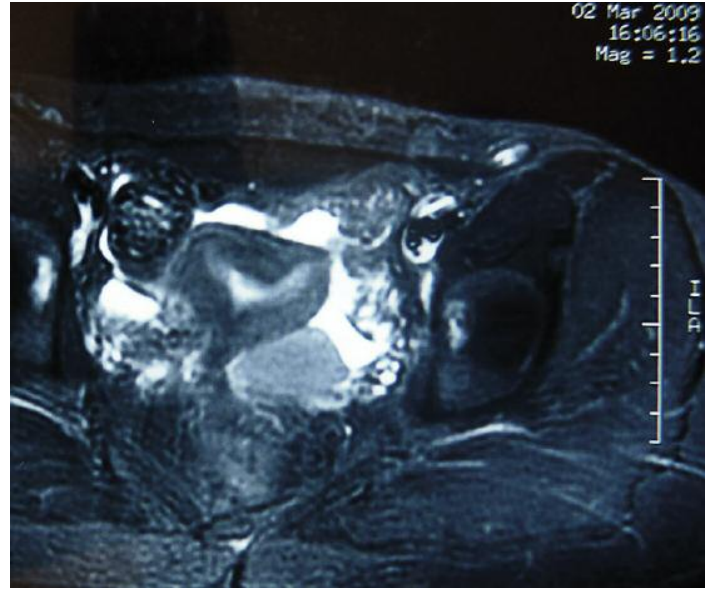

Figure 1. Transverse MRI view of the arcuate uterus

The intrauterine catheter was removed and a Lippes loop intrauterine device (IUD) was inserted at a 1-month medical visit. The IUD was placed as a stent to maintain utero-vaginal anastomosis. The US examination was within normal limits. Vaginal depth was $8 \mathrm{~cm}$. Menstruation was restored with a delay of 1 month postoperatively. At the $12^{\text {th }}$ month examination, the IUD was removed and hysterosalpingography examination was performed. Hysterosalpingography revealed patent vaginal and cervical canals (Figure 4).

Cervical agenesis is usually seen with partial or complete vaginal agenesis. Since it is an uncommon anomaly, there is still no consensus about the treatment. First line treatment in reconstruction of agenesis can be conducted by repetitive dilatation and expansions [5]. However, in these techniques, multiple stages are necessary.

In cervicovaginal agenesis reconstruction, the most commonly used technique has been cylindrical stent assisted, split-thickness skin graft, described by McIndoe and Banister [11]. Stenosis at the proximal one third of the vagina is a disadvantage of this method, which is seen in $21-42 \%$ of cases [12, 13].

The labial pocket flap was expanded using labia minora flaps [14] and a tissue expander [15]; these

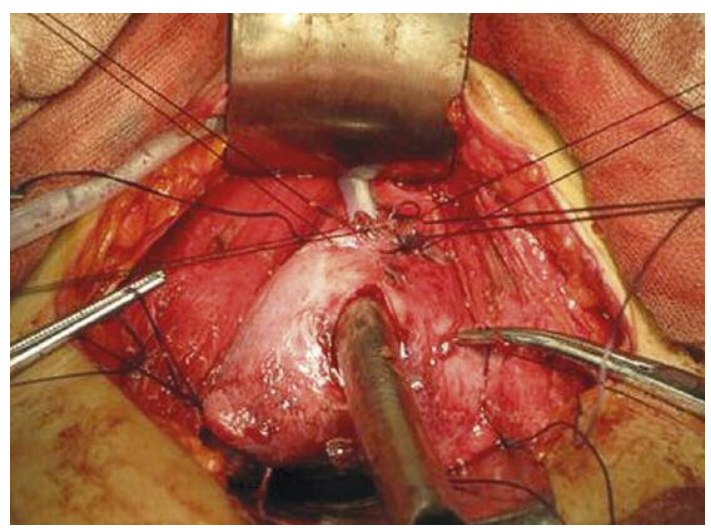

Figure 3. Distal aspect of the pudendal thigh flap with anterior abdominal wall 


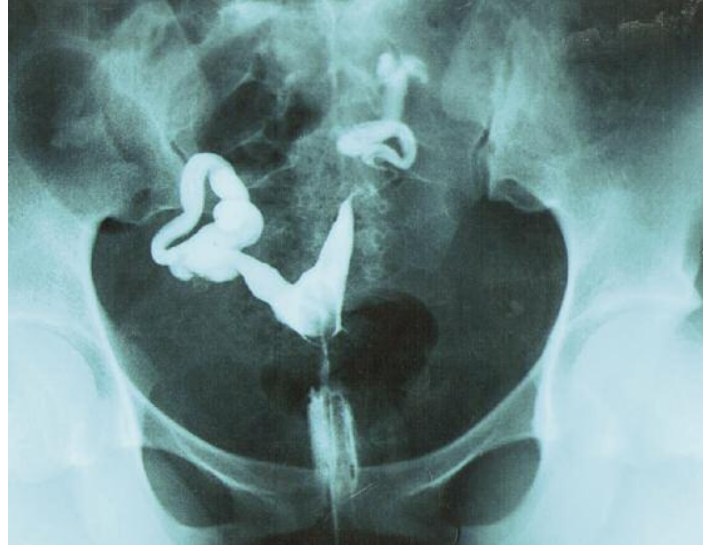

Figure 4. Postoperative appearance of tubal patency by hysterosalpingography

are the first ones to come to mind amongst the local-regional flaps in agenesis reconstruction. Since the tissue provided is limited, the use of these local flaps is limited in complete agenesis cases. The most important disadvantage of musculocutaneous flaps such as gracilis [16] and rectus abdominis [17] is that they cause bulky tissue formation. Some pediatric surgeons and urologists utilize a segment of bowel such as ileum, cecum, jejunum, sigmoid colon or peritoneum to create a vagina $[12,18,19]$. The advantages of this technique are its low contraction risk, elimination of the need for molds, providing lubrication and resistance against traumas [12]. However, this technique requires a laparotomy and bowel reanastomosis.

Fedele modified the Vecchietti technique and described laparoscopy assisted uterovestibular anastomosis [20]. Fedele et al. reported regular menstrual bleeding for all 12 patients in their series via this technique [21]. They mentioned that there was no need of vaginal molding after surgery. But they recommended inhibition of bleeding from functioning endometrium with gonadotropin-releasing hormone analogs. The advantages of laparoscopic access are shorter postoperative stay, less postoperative pain and no laparotomy scar. However, long-term vaginal molding was needed after some laparoscopic interventions [22]. Vecchietti's procedure requires special care in the graduation of the threads' tension. Oral analgesia was usually needed for pain control during the procedure.

The pudendal thigh flap used in our case is an easily prepared fasciocutaneous flap. It is a skin flap based on the groin crease, first described by Wee and Joseph [23]. It has been frequently utilized for perineal and vaginal reconstruction and recto- or vesico-vaginal fistula repair, as it has been described as easy to harvest, thin, pliable and sensate [24, 25]. Since it is a vascular tissue, it is superior to a skin graft (McIndoe method) or other grafts. It minimizes the risk of contraction or stenosis in the flaps. The main advantage of our technique is that there is no need to use long-term postoperative molds, dilators, or obturators to avoid stenosis or contraction of the vagina and the donor site scars are well hidden under the pubic line.

When a functional result such as pregnancy is considered, it is not possible to absolutely state which of these operative techniques are superior. As the condition is rare, the ability to perform longterm follow-up studies comparing the various options is limited. The most frequently used method has been the Mclndoe technique $[7,26]$. When compared to the McIndoe technique, which has a high rate of stenosis [12], a higher chance of pregnancy with flaps can be stated. In the 1-year follow-up of our case, uterovaginal opening was achieved, functional endometrium was protected and partial tubal passage was present. The findings were confirmed by hysterosalpingography.

The most important disadvantage of the pudendal thigh flap is hirsutism. It is reported that the mucosa which is maintained by the Mclndoe technique is much more similar to normal vaginal mucosa. In cases of insufficient atrophy, postoperative depilation may be necessary [10]. In our case, increased hair growth was observed during the 1- and 3-month follow-up with a decrease in the 6-month follow-up. At the end of the postoperative $1^{\text {st }}$ year, hirsutism had almost completely disappeared.

In conclusion, various techniques in construction of the vagina and cervix agenesis have been described in the literature. Reconstruction cases using thigh flaps are very few and the efficacy of the technique for pregnancy is still not clear. However, it should be kept in mind as a simple technique in cervicovaginal agenesis reconstruction which eliminates the need for complex surgical processes.

\section{References}

1. Buttram VC Jr. Mullerian anomalies and their management. Fertil Steril 1983; 40: 159-63.

2. Griffin JE, Edwards C, Madden JD, Harrod MJ, Wilson JD. Congenital absence of the vagina. The Mayer-Rokitansky-KusterHauser syndrome. Ann Intern Med 1976; 85: 224-36.

3. Fujimoto VY, Miller JH, Klein NA, Soules MR. Congenital cervical atresia: report of seven cases and review of the literature. Am J Obstet Gynecol 1997; 177: 1419-25.

4. Geary WL, Weed JC. Congenital atresia of the uterine cervix. Obstet Gynecol 1973; 42: 213-7.

5. Bedner R, Rzepka-Górska I, Błogowska A, Malecha J, Kośmider M. Effects of a surgical treatment of congenital cervicovaginal agenesia. J Pediatr Adolesc Gynecol 2004; 17: 327-30.

6. Gürlek A, Aslan SS, Frat C, Ozturk-Ersoz A, Burak F. Combined cervical and vaginal reconstruction with prefabricated pudendal thigh flap in a case with cervical and vaginal agenesis (MURCS syndrome): a new and original technique. Ann Plast Surg 2008; 61: 88-93.

7. Deffarges JV, Haddad B, Musset R, Paniel BJ. Utero-vaginal anastomosis in women with uterine cervix atresia: longterm follow-up and reproductive performance. A study of 18 cases. Hum Reprod 2001; 16: 1722-5. 
8. Giraldo F. Cutaneous neovaginoplasty using the Málaga flap (vulvoperineal fasciocutaneous flap): a 12-year follow-up. Plast Reconstr Surg 2003; 111: 1249-56.

9. Fliegner JR, Pepperell RJ. Management of vaginal agenesis with a functioning uterus. Is hysterectomy advisable? Aust N Z J Obstet Gynaecol 1994; 34: 467-70.

10. Goldwyn RM. History of attempts to form a vagina. Plast Reconstr Surg 1977; 59: 319-29.

11. Banister JB, Mclndoe AH. Congenital absence of the vagina, treated by means of an indwelling skin-graft. Proc $R$ Soc Med 1938; 31: 1055-6.

12. Chen HC, Chana JS, Feng GM. A new method for vaginal reconstruction using a pedicled jejunal flap. Ann Plast Surg 2003; 51: 429-31.

13. Buss JG, Lee RA. McIndoe procedure for vaginal agenesis: results and complications. Mayo Clin Proc 1989; 64: 758-61.

14. Flack CE, Barraza MA, Stevens PS. Vaginoplasty: combination therapy using labia minora flaps and lucite dilators: preliminary report. J Urol 1993; 150: 654-6.

15. Patil U, Hixson FP. The role of tissue expanders in vaginoplasty for congenital malformations of the vagina. Br J Urol 1992; 70: 554-7.

16. McCraw JB, Massey FM, Shanklin KD, Horton CE. Vaginal reconstruction with gracilis myocutaneous flaps. Plast Reconstr Surg 1976; 58: 176-83.

17. Skene Al, Gault DT, Woodhouse CR, Breach NM, Thomas JM. Perineal, vulval and vaginoperineal reconstruction using the rectus abdominis myocutaneous flap. Br J Surg 1990; 77: 635-7.

18. Alborzi S, Momtahan M, Parsanezhad ME, Yazdani M. Successful treatment of cervical aplasia using a peritoneal graft. Int J Gyneacol Obst 2005; 88: 299-302.

19. Cam C, Celik C, Sakalli M, Baykal B, Karateke A. Introitocervical sigmoid colon transpositioning procedure. Cent Eur J Med 2008; 5: 184-8.

20. Fedele L, Busacca M, Candiani M, Vignali M. Laparoscopic creation of a neovagina in Mayer-Rokitansky-Küster-Hauser syndrome by modification of Vecchietti's operation. Am J Obstet Gynecol 1994; 171: 268-9.

21. Fedele L, Bianchi S, Frontino G, Berlanda N, Montefusco S, Borruto F. Laparoscopically assisted uterovestibular anastomosis in patients with uterine cervix atresia and vaginal aplasia. Fertil Steril 2008; 89: 212-6.

22. Folgueira G, Perez-Medina T, Martinez-Cortes L, et al. Laparoscopic creation of a neovagina in Mayer-Rokitansky-Küster-Hauser syndrome by modified Vecchietti's procedure. Eur J Obstet Gynecol Reprod Biol 2006; 127: 240-3.

23. Wee JT, Joseph VT. A new technique of vaginal reconstruction using neurovascular pudendal-thigh flaps: a preliminary report. Plast Reconstr Surg 1989; 83:701-9.

24. Joseph VT. Pudendal-thigh flap vaginoplasty in the reconstruction of genital anomalies. J Pediatr Surg 1997; 32: 62-5.

25. Selvaggi G, Monstrey S, Depypere H, et al. Creation of a neovagina with use of a pudendal thigh fasciocutaneous flap and restoration of uterovaginal continuity. Fertil Steril 2003; 80: 607-11.

26. Acién P, Acién MI, Quereda F, Santoyo T. Cervicovaginal agenesis: spontaneous gestation at term after previous reimplantation of the uterine corpus in a neovagina: case report. Hum Reprod 2008; 23: 548-53. 